\title{
Perceived changes in the knowledge and confidence of doctors and midwives to manage obstetric emergencies following completion of an Advanced Life Support in Obstetrics course in Australia
}

\author{
Laura J. M. WALKER, ${ }^{1}$ Catherine M. FETHERSTON ${ }^{2}$ and Anne McMurray ${ }^{3}$ \\ ${ }^{1}$ School of Nursing and Midwifery, Curtin University, Perth, WA, ${ }^{2}$ Associate Dean Learning and Teaching, School of Health Professions, \\ Murdoch University, Perth, WA, and ${ }^{3}$ School of Nursing and Midwifery, Griffith University, Gold Coast, Qld, Australia
}

\begin{abstract}
Background: The Advanced Life Support in Obstetrics (ALSO) course is an internationally recognised interprofessional course to support health professionals to develop and maintain the knowledge and skills to manage obstetric emergencies. Aims: This study investigated changes in confidence and perceived changes in the knowledge of doctors and midwives to manage specific obstetric emergency situations following completion of an ALSO course in Australia.

Methods: A prospective repeated-measures survey design was used to survey 165 course attendees from four Australian states pre- and postcourse and at six weeks $(n=101)$. Data were analysed using a Friedman two-way repeated-measures analysis of variance and the Wilcoxon signed rank test.

Results: There was a significant improvement in confidence and perceived knowledge of the recommended management of all 17 emergency situations immediately postcourse $(P<0.001)$ and at six weeks postcourse $(P<0.001)$ when compared to precourse levels for both groups of health professionals. However, a significant decrease in knowledge and confidence for many emergency situations from immediately postcourse to six weeks postcourse $(P<0.05)$ was also observed in both groups.

Conclusions: Completion of the Australian ALSO course in Australia has a positive effect on the confidence and perceived knowledge of doctors and midwives to manage obstetric emergencies. However, there needs to be some means of reinforcing the effects of the course for longer term maintenance of knowledge and confidence.
\end{abstract}

2 Key words: Advanced Life Support in Obstetrics, confidence, doctors, knowledge, midwives, obstetric emergencies.

\section{Introduction}

In Australia, most women have an uneventful pregnancy, labour and birth resulting in a healthy baby. ${ }^{1}$ However, recent years have seen a rise in obesity, maternal age, Caesarean sections, multiple pregnancies and comorbidities in women of childbearing age, all of which have increased the risks of adverse outcomes. ${ }^{2}$ Whilst maternal death is unusual in Australia, a woman dies in circumstances associated with childbirth approximately every two weeks, and many of these deaths have been linked to preventable factors such as a lack of communication and teamwork within both obstetric and midwifery teams. ${ }^{3}$ These

Correspondence: Lecturer Laura J. M. Walker, School of Nursing and Midwifery, Curtin University, Building 405 Room 414, GPO Box U1987, Perth, WA 6845, Australia.

1 Emails: laura.walker@curtin.edu.au,ljm56@bigpond.com

Received 22 fanuary 2013; accepted 29 May 2013. concerns highlight the need for all maternity care providers to regularly update their emergency skills and knowledge for early identification of maternal and neonatal risk factors and problems and enhance their communication and teamwork competence to provide effective management of maternal collapse. ${ }^{2}$

The Advanced Life Support in Obstetrics (ALSO) course is an interprofessional course to support health professionals to develop and maintain the knowledge and skills to manage obstetric emergencies. Obstetric emergency training is integral to the education of those providing intrapartum care and should be considered mandatory. ${ }^{4,5}$ Recognised courses that provide scenario-based training with mannequins, ${ }^{6-8}$ including the ALSO course, ${ }^{2}$ have the capacity to improve the quality and safety of maternity care in Australia. However, although these courses can supplement and consolidate clinical experience, they cannot be used as a substitute for it.

Much of the work around obstetric emergency training promotes a model of having health professionals who work together and train together. ${ }^{9-11}$ The often peripatetic 
workforce in Australia can also benefit from centralised courses like ALSO, which promote internationally recognised, evidence-based obstetric emergency skills that are transferable to any workplace. Although the effectiveness of the ALSO course has been evaluated several times in the United States of America (USA) ${ }^{12-15}$ and ALSO outcomes have been measured in a hospital in Tanzania, ${ }^{16}$ no other published research evaluating the ALSO course was identified. To this end, the aims of this study were to measure changes in participants' confidence and perceived knowledge to manage specific obstetric situations immediately after completion of an ALSO course in Australia and to reassess six weeks later to determine retention of confidence and perceived knowledge.

\section{Materials and Methods}

A prospective repeated-measures survey design was undertaken over three time periods: precourse, postcourse and six weeks postcourse, using a questionnaire adapted, with permission, from an instrument used to investigate ALSO courses in the USA. ${ }^{14}$ The revised survey consisted of five-point rank-ordered responses Likert scale questions that measured perceptions of knowledge and confidence to manage the obstetric emergency situations covered in the ALSO curriculum, detailed in Table 1.

In each questionnaire, participants were asked to rate their current knowledge about the recommended management of specified obstetric situations and then to rate their level of confidence to clinically manage the same situations. The rating scale responses on the 1 to 5 scale for level of knowledge were $1=$ poor to $5=$ excellent. Responses on the 1 to 5 rating scale for level of confidence were $1=$ not confident to $5=$ extremely confident. Sociodemographic variables included participants' gender, profession, job title, years of clinical practice and current working area. The six weeks postcourse questionnaire also included several openended questions about various aspects of the course, including whether or not participants had had any obstetric

Table 1 Situations taught in the ALSO course

\begin{tabular}{l}
\hline Interpreting cardiotocograph (CTG) traces \\
Forceps-assisted births \\
Vacuum-assisted births \\
Shoulder dystocia \\
Postpartum haemorrhage (PPH) \\
Umbilical cord prolapse \\
Pre-eclampsia/eclampsia \\
Vaginal breech births \\
Preterm labour (PTL) \\
Antepartum haemorrhage (APH) \\
Labour dystocia \\
Maternal resuscitation \\
Neonatal resuscitation (NNR) \\
Maternal venous thrombosis \\
First-trimester bleeding \\
Perinatal loss
\end{tabular}

situations at work in which they had used the knowledge or skills learnt during their recent ALSO course. Following permission to conduct the study by the Australian ALSO Executive Board and ethics approval by Murdoch University Human Research Ethics Committee, all participants attending one of four consecutive ALSO courses in Western Australia, New South Wales, Victoria and Queensland from June to December 2010 were invited by email to participate. At the course registration, those attendees who consented were given an envelope containing a coded consent form and coded precourse questionnaire. Completed questionnaires were returned to the envelope, sealed and 'posted' into a survey submission box. This process was repeated on completion of the course, and a third questionnaire was posted to the participants six weeks after completion of the course. One of the objectives in choosing the six-week time frame was to examine whether there was any decline in confidence and/or perceived knowledge before participants were exposed to intervening variables, such as other courses or training, which could potentially confound the outcomes. Each questionnaire asked the same questions about the obstetric situations taught in the course and intended to establish the participant's perceived knowledge and confidence about each obstetric situation at that particular time, thereby allowing comparisons across the three time periods.

Prior to the evaluation, a pilot study $(n=29)$ was undertaken to establish reliability and face and content validity of the questionnaires, resulting in a Cronbach's alpha of 0.92 and 0.97 for the pre- and postcourse questionnaires, respectively. As no changes to the questionnaires were deemed necessary, the data from the pilot study were included in the main study.

Analysis was conducted using SPSS $17^{\circledR}$ for Windows (2008) with descriptive data reporting frequencies, percentages, median and interquartile range (IQR) or mean and standard deviation according to normality. A Friedman two-way repeated-measures analysis of variance for related samples was used to investigate the impact of the ALSO course on the participants' confidence in their knowledge and ability to manage the different obstetric emergency situations. Follow-up pairwise comparisons (precourse to immediately postcourse; precourse to six weeks postcourse; and immediately postcourse to six weeks postcourse) using the Wilcoxon signed rank test with a Bonferroni correction were subsequently performed. After analysing the results for all categories of participants, the sample was then split to investigate differences in the findings for the doctors and midwives.

Effect size $(r)$ was calculated, ${ }^{17}$ and the size of the effect was described as small $(r=0.1)$, medium $(r=0.3)$ or large $(r=0.5) .{ }^{18}$ All $P$ levels lower than 0.05 were considered significant.

\section{Results}

The sampling frame consisted of 242 course attendees (98 doctors and 144 midwives), of whom 170 agreed to 
Table 2 Professional positions held by study medical participants

\begin{tabular}{lcc}
\hline & $\begin{array}{c}\text { Pre- and } \\
\text { postcourse } \\
\text { Participants } \\
n=62(\%)\end{array}$ & $\begin{array}{c}\text { 6/52 postcourse } \\
\text { Participants } \\
n=35(\%)\end{array}$ \\
Occupation of doctors & $1(2)$ & $1(3)$ \\
\hline O\&G Consultant & $8(13)$ & $5(14)$ \\
GP Obstetrician & $2(3)$ & $2(6)$ \\
O\&G Registrar & $21(34)$ & $7(20)$ \\
O\&G Resident & $3(5)$ & $2(6)$ \\
Flight Doctor & $17(27)$ & $15(43)$ \\
District Medical & & \\
Officer/Medical & $5(8)$ & $3(8)$ \\
Officer & $4(6)$ & 0 \\
GP/GP trainee & & \\
Consultant/Senior & $1(2)$ & 0 \\
Registrar (non & & \\
O\&G) & & \\
Other & &
\end{tabular}

participate in the study, although five were subsequently excluded due to incomplete data. This resulted in an adequate sample size ${ }^{19}$ of $165(68 \%)$, including 62 doctors $(37.6 \%)$ and 102 midwives (61.8\%). One participant's profession was unknown.

One hundred and one participants (61\% of the original 165 participants) completed the six weeks postcourse questionnaire, including 65 (65\%) midwives and 35 (35\%) doctors. All midwives were female, with 14 male and 21 female doctors. Although the midwives did not generally specify their professional status, Table 2 illustrates the doctors' professional positions at the different data collection times.

\section{Sociodemographic data}

Precourse data were unavailable for ALSO course attendees who chose not to participate in the study, and therefore, no demographic comparisons can be made between survey responders and nonresponders. However, sampling bias was minimised by the relatively high response rate where $63.3 \%$ of doctors and $70.8 \%$ of midwives in the sampling frame responded to the preand postcourse survey. Amongst the study participants, years of experience for doctors ranged from 1 to 32 with a median of 4 (IQR: 2, 10), whereas midwives generally had more experience with a range of 1-38 years, median 15 (IQR: $5.75,25)$. The majority of study participants indicated their work involved some aspects of maternity care, with only $13 \%$ having no direct involvement in the clinical care of maternity patients. However, a larger proportion of the doctors were not involved in the clinical care of maternity patients both in the initial sample (28\%) and in the six-week sample $(29 \%)$ compared with midwives (4\% of both samples).

\section{Perceptions of knowledge}

Perceptions of knowledge related to the recommended management of all of the obstetric situations measured increased significantly from precourse to six weeks postcourse, $X^{2}=1452.25$ (corrected for ties), $d f=50$, $N-$ ties $=88, P<0.001$. These findings are presented in Table 3.

Follow-up pairwise comparisons at the three time periods showed a significant increase in perceptions of knowledge related to all the obstetric situations from precourse to immediately postcourse for both professional groups $(P<0.001, r=0.64-0.91)$, which was sustained at six weeks postcourse $(P<0.001, r=0.76-0.92)$.

\section{Perceptions of confidence}

Participants' confidence to clinically manage all of the obstetric situations measured increased significantly from precourse to six weeks postcourse, $X^{2}=2088.42$ (corrected for ties), $d f=53, N-$ ties $=93, P<0.001$. These findings are presented in Table 4.

Follow-up pairwise comparisons showed a significant increase in the confidence of both professional groups to clinically manage all the obstetric situations from precourse to immediately postcourse $(P<0.001, r=$ 0.79-0.93), which was sustained for six weeks following the course $(P<0.001, r=0.74-0.95)$.

\section{Retention of knowledge and confidence}

Although both professional groups experienced overall significantly increased levels of perceived knowledge and confidence for up to six weeks following the ALSO course, there were significant decreases in both groups, to varying degrees, in the perceived knowledge and/or confidence for many of the obstetric situations measured during the period from immediately postcourse to six weeks postcourse. The six weeks postcourse question as to whether participants had had any obstetric situations at work in which they had used the knowledge or skills learnt during their recent ALSO course revealed that 54\% of doctors and $34 \%$ of midwives had not. Several participants added explanations which included:

Have been on holidays but know I will use them extensively on my return

Working in medical wards since

Not often

Not yet thankfully

Only because I have now rotated onto a different unit. I will be undertaking GP obstetrician work next year and I have no doubt that ALSO skills/knowledge will be invaluable 
Table 3 Changes in perceived knowledge about the management of obstetric situations from precourse to six weeks post-course

\begin{tabular}{|c|c|c|c|c|c|}
\hline Obstetric situation & Participants & $\begin{array}{c}\text { Precourse } \\
\text { Median (IQR) }\end{array}$ & $\begin{array}{l}\text { Six weeks postcourse } \\
\text { Median (IQR) }\end{array}$ & $\begin{array}{l}\text { Significance } \\
\text { (two-tailed) }\end{array}$ & Effect size \\
\hline \multirow[t]{2}{*}{ Interpreting intrapartum CTG traces } & Midwives & $4(3,4)$ & $4(4,4)$ & $<0.001$ & 0.82 \\
\hline & Doctors & $3(3,4)$ & $4(3,4)$ & $<0.001$ & 0.79 \\
\hline \multirow[t]{2}{*}{ Forceps-assisted births } & Midwives & $3(2,3)$ & $4(3,4)$ & $<0.001$ & 0.80 \\
\hline & Doctors & $2(2,3)$ & $3(3,4)$ & $<0.001$ & 0.82 \\
\hline \multirow[t]{2}{*}{ Maternal venous thrombosis } & Midwives & $3(3,3)$ & $4(3,4)$ & $<0.001$ & 0.91 \\
\hline & Doctors & $3(3,4)$ & $4(4,4)$ & $<0.001$ & 0.93 \\
\hline \multirow[t]{2}{*}{ Postpartum haemorrhage } & Midwives & $4(3,4)$ & $4(4,5)$ & $<0.001$ & 0.89 \\
\hline & Doctors & $4(3,4)$ & $4(4,5)$ & $<0.001$ & 0.90 \\
\hline \multirow[t]{2}{*}{ Materna Maternal resuscitation } & Midwives & $3(3,4)$ & $4(4,4)$ & $<0.001$ & 0.83 \\
\hline & Doctors & $3(3,4)$ & $4(4,5)$ & $<0.001$ & 0.87 \\
\hline \multirow[t]{2}{*}{ Pre-eclampsia } & Midwives & $3(3,4)$ & $4(4,4)$ & $<0.001$ & 0.84 \\
\hline & Doctors & $3(3,4)$ & $4(4,5)$ & $<0.001$ & 0.85 \\
\hline \multirow[t]{2}{*}{ Eclampsia } & Midwives & $3(3,4)$ & $4(4,4)$ & $<0.001$ & 0.94 \\
\hline & Doctors & $3(3,4)$ & $4(3,4)$ & 0.002 & 0.58 \\
\hline \multirow[t]{2}{*}{ Umbilical cord prolapse } & Midwives & $3(3,4)$ & $4(4,4.5)$ & $<0.001$ & 0.87 \\
\hline & Doctors & $3(2,3.5)$ & $4(3,4)$ & $<0.001$ & 0.91 \\
\hline \multirow[t]{2}{*}{ Vaginal breech births } & Midwives & $3(2,3)$ & $4(3,4)$ & $<0.001$ & 0.84 \\
\hline & Doctors & $2(2,3)$ & $3(3,4)$ & $<0.001$ & 0.86 \\
\hline \multirow[t]{2}{*}{ Neonatal resuscitation } & Midwives & $4(3,4)$ & $4(4,5)$ & $<0.001$ & 0.82 \\
\hline & Doctors & $3(2.5,4)$ & $4(3,4.25)$ & $<0.001$ & 0.81 \\
\hline \multirow[t]{2}{*}{ Vacuum-assisted births } & Midwives & $3(3,3)$ & $4(4,4)$ & $<0.001$ & 0.86 \\
\hline & Doctors & $3(2,4)$ & $4(3,4)$ & $<0.001$ & 0.77 \\
\hline \multirow[t]{2}{*}{ Shoulder dystocia } & Midwives & $3(3,4)$ & $4(4,5)$ & $<0.001$ & 0.91 \\
\hline & Doctors & $3(2.5,3.5)$ & $4(4,5)$ & $<0.001$ & 0.96 \\
\hline \multirow[t]{2}{*}{ Antepartum haemorrhage } & Midwives & $3(3,4)$ & $4(4,4)$ & $<0.001$ & 0.89 \\
\hline & Doctors & $4(3,4)$ & $4(3,4)$ & $<0.001$ & 0.79 \\
\hline \multirow[t]{2}{*}{ Preterm labour } & Midwives & $3(3,4)$ & $4(4,4.5)$ & $<0.001$ & 0.86 \\
\hline & Doctors & $3(3,4)$ & $4(3,4)$ & $<0.001$ & 0.88 \\
\hline \multirow[t]{2}{*}{ First-trimester bleeding } & Midwives & $3(3,3.5)$ & $4(3.25,4)$ & $<0.001$ & 0.82 \\
\hline & Doctors & $4(3,4)$ & $4(4,5)$ & 0.012 & 0.59 \\
\hline \multirow[t]{2}{*}{ Labour dystocia } & Midwives & $3(3,4)$ & $4(4,4)$ & $<0.001$ & 0.85 \\
\hline & Doctors & $3(2,4)$ & $4(3,4)$ & $<0.001$ & 0.86 \\
\hline \multirow[t]{2}{*}{ Families experiencing perinatal loss } & Midwives & $3(3,4)$ & $4(4,4)$ & $<0.001$ & 0.76 \\
\hline & Doctors & $3(2,4)$ & $4(3,4)$ & $<0.001$ & 0.90 \\
\hline
\end{tabular}

The areas where a decrease in knowledge and/or confidence occurred for each professional group in the six weeks following successful completion of the course are outlined in Table 5.

\section{Discussion}

This study's findings support those from other ALSO course evaluations conducted in the USA that found the course increased participants' levels of comfort or confidence. $^{12-14}$ Although this study did not measure changes in knowledge, it is reassuring to note the increase in perceptions of knowledge following the Australian ALSO course. This study extended previous findings in that the USA studies focussed largely on medical practitioners, whereas this study has contributed knowledge related to both doctors and midwives. Adding strength to the findings was the recruitment of participants from different states around Australia over several courses, which resulted in a representative study sample of typical ALSO course attendees. Interestingly, many of the doctors reported lower levels of experience than the midwives, which suggests that they may have been either recent graduates or not directly involved in day-to-day obstetric care.

Despite the overall increase in confidence and knowledge at both the completion of the course and at six weeks, as can be seen in Table 5, analysis of specific emergency situations revealed a decrease in knowledge and/or confidence from immediately postcourse to six weeks postcourse for many of the emergency situations measured. This observed variation may be explained by either the complicated nature of these procedures or the rarity with which some of them are practised, either because the procedures themselves are uncommon or because these doctors and midwives were not currently exposed to the particular practice issue that would help them consolidate their learning. For instance, in Australia, 
Table 4 Changes in confidence to clinically manage obstetric situations from precourse to six weeks post-course

\begin{tabular}{|c|c|c|c|c|c|}
\hline Obstetric situation & Participants & $\begin{array}{c}\text { Precourse } \\
\text { Median (IQR) }\end{array}$ & $\begin{array}{l}\text { Six-weeks postcourse } \\
\text { Median (IQR) }\end{array}$ & $\begin{array}{l}\text { Significance } \\
\text { (two-tailed) }\end{array}$ & Effect size \\
\hline \multirow[t]{2}{*}{ Interpreting intrapartum CTG traces } & Midwives & $4(3,4)$ & $4(4,4)$ & $<0.001$ & 0.97 \\
\hline & Doctors & $3(2.5,4)$ & $4(3,4)$ & $<0.001$ & 0.94 \\
\hline \multirow[t]{2}{*}{ Forceps-assisted births } & Midwives & $2(2,3)$ & $3(3,4)$ & $<0.001$ & 0.85 \\
\hline & Doctors & $2(2,3)$ & $3(3,4)$ & $<0.001$ & 0.90 \\
\hline \multirow[t]{2}{*}{ Maternal venous thrombosis } & Midwives & $3(2.3,3)$ & $4(3,4)$ & $<0.001$ & 0.81 \\
\hline & Doctors & $3(3,4)$ & $4(4,4.25)$ & $<0.001$ & 0.81 \\
\hline \multirow[t]{2}{*}{ Postpartum haemorrhage } & Midwives & $4(3,4)$ & $4(4,5)$ & $<0.001$ & 0.93 \\
\hline & Doctors & $4(3,4)$ & $4(4,5)$ & $<0.001$ & 0.86 \\
\hline \multirow[t]{2}{*}{ Maternal Maternal resuscitation } & Midwives & $3(3,4)$ & $4(4,4)$ & $<0.001$ & 0.90 \\
\hline & Doctors & $3(3,4)$ & $4(4,5)$ & $<0.001$ & 0.94 \\
\hline \multirow{2}{*}{ Pre-eclampsia } & Midwives & $3(3,4)$ & $4(4,4)$ & $<0.001$ & 0.88 \\
\hline & Doctors & $3(3,4)$ & $4(4,5)$ & $<0.001$ & 0.87 \\
\hline \multirow[t]{2}{*}{ Eclampsia } & Midwives & $3(3,4)$ & $4(4,4)$ & $<0.001$ & 0.93 \\
\hline & Doctors & $3(2,3)$ & $4(3,4)$ & $<0.001$ & 0.82 \\
\hline \multirow[t]{2}{*}{ Umbilical cord prolapse } & Midwives & $3(3,4)$ & $4(4,4)$ & $<0.001$ & 0.89 \\
\hline & Doctors & $2(2,3)$ & $4(3,4)$ & $<0.001$ & 0.91 \\
\hline \multirow{2}{*}{ Breech: Lovsett manoeuvre } & Midwives & $2(2,3)$ & $4(3,4)$ & $<0.001$ & 0.87 \\
\hline & Doctors & $2(1,3)$ & $3(3,4)$ & $<0.001$ & 0.90 \\
\hline \multirow[t]{2}{*}{ Breech: Mauriceau Smellie Veit manoeuvre } & Midwives & $2(2,3)$ & $4(3,4)$ & $<0.001$ & 0.87 \\
\hline & Doctors & $2(1.5,3)$ & $3(3,4)$ & $<0.001$ & 0.90 \\
\hline \multirow[t]{2}{*}{ Neonatal resuscitation } & Midwives & $4(3,4)$ & $4(4,5)$ & $<0.001$ & 0.83 \\
\hline & Doctors & $3(3,4)$ & $4(3.75,4.25)$ & $<0.001$ & 0.85 \\
\hline \multirow[t]{2}{*}{ Vacuum-assisted births } & Midwives & $3(2,3)$ & $4(3,4)$ & $<0.001$ & 0.84 \\
\hline & Doctors & $3(2,3)$ & $4(3,4)$ & $<0.001$ & 0.90 \\
\hline \multirow[t]{2}{*}{ Shoulder dystocia: HELPERR manoeuvres } & Midwives & $3(3,4)$ & $4(4,5)$ & $<0.001$ & 0.91 \\
\hline & Doctors & $3(2,3)$ & $4(4,5)$ & $<0.001$ & 0.89 \\
\hline \multirow[t]{2}{*}{ Antepartum haemorrhage } & Midwives & $3(3,4)$ & $4(4,4)$ & $<0.001$ & 0.92 \\
\hline & Doctors & $3(3,4)$ & $4(3.75,5)$ & $<0.001$ & 0.89 \\
\hline \multirow[t]{2}{*}{ Preterm labour } & Midwives & $3(3,4)$ & $4(4,4)$ & $<0.001$ & 0.90 \\
\hline & Doctors & $3(3,4)$ & $4(4,4)$ & $<0.001$ & 0.86 \\
\hline \multirow[t]{2}{*}{ First trimester bleeding } & Midwives & $3(3,3)$ & $4(3,4)$ & $<0.001$ & 0.89 \\
\hline & Doctors & $4(3,4)$ & $4(4,5)$ & $<0.001$ & 0.85 \\
\hline \multirow{2}{*}{ Labour dystocia } & Midwives & $3(3,4)$ & $4(4,4)$ & $<0.001$ & 0.85 \\
\hline & Doctors & $3(2,4)$ & $4(3,4)$ & $<0.001$ & 0.90 \\
\hline \multirow[t]{2}{*}{ Families experiencing perinatal loss } & Midwives & $3(3,4)$ & $4(3.5,4)$ & $<0.001$ & 0.66 \\
\hline & Doctors & $3(2,4)$ & $4(3,4)$ & $<0.001$ & 0.88 \\
\hline
\end{tabular}

almost all breech babies are born by Caesarean section, ${ }^{20}$ so although it is essential that doctors and midwives have a working knowledge of how to safely assist a vaginal breech birth, in reality, this rarely happens.

In regard to caring for families experiencing a perinatal loss, although babies of 'low-risk' women can unexpectedly die at birth, it is generally babies of 'high-risk' women who are more likely to become sick or die. ${ }^{21}$ Such 'high-risk' women are usually booked to birth at a tertiary unit with specialist obstetric, midwifery and neonatal teams to provide the expert care they require. Consequently, many midwives and doctors do not have the opportunity to care for these families.

The decline in confidence regarding neonatal resuscitation (NNR) may have been due to aspects of training such as the need to demonstrate intermittent positive pressure ventilation and concurrent cardiac compressions, which occurs infrequently. ${ }^{21}$ This finding is supported by
Sørensen et $a .^{22}$ who also found a significant decrease in confidence with NNR nine months after an obstetric skills' training course, explaining it on the basis that NNR is managed less frequently than the other skills covered in their training programme.

The use of cardiotocographs (CTGs) intrapartum is fairly widespread throughout Australia, yet both doctors and midwives also reported a significant decrease in confidence in this area six weeks after the course. These findings are likely to be related to levels of precourse knowledge and expertise, ${ }^{23}$ but support similar findings of a previous Australian study ${ }^{24}$ which found that completion of an intrapartum fetal surveillance programme did not necessarily increase confidence to interpret CTG traces.

Unexpectedly, there were additional obstetric situations where only the doctors and not the midwives reported a decline in their confidence and/or perceived knowledge at the six-week follow-up. Table 2 indicates that only $29 \%$ of 


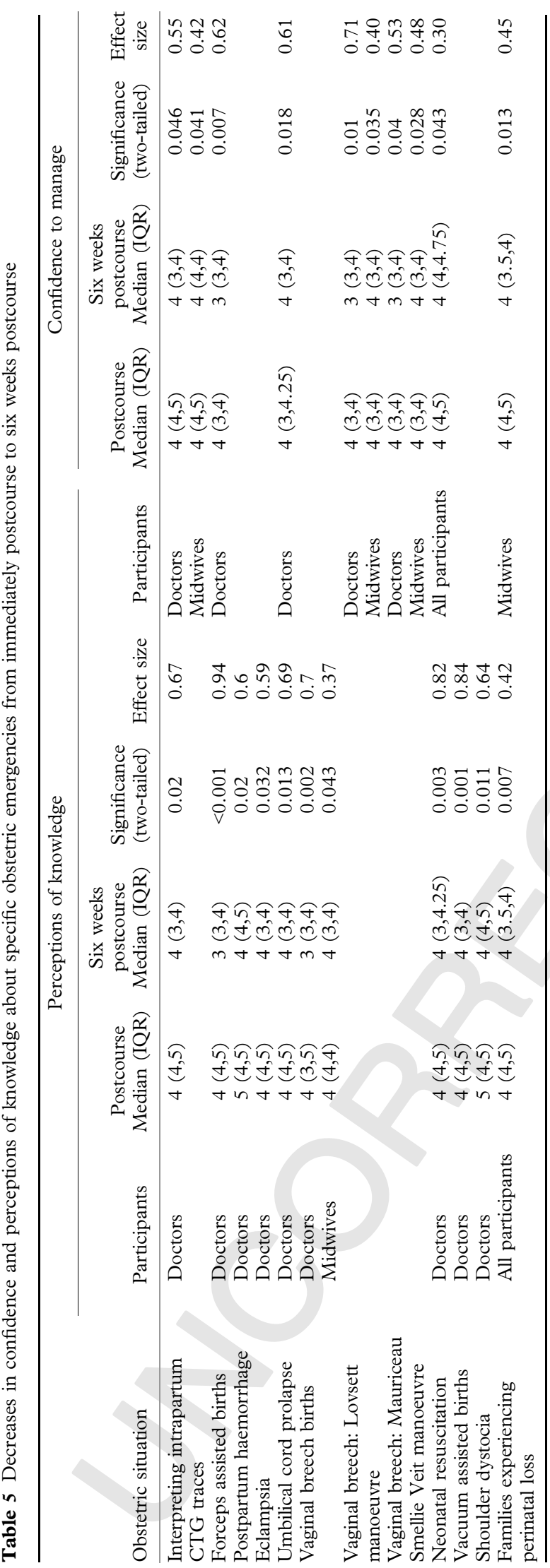

these doctors were working exclusively in obstetrics, so many of the situations would be relatively uncommon for the clinicians who were not regularly providing intrapartum care. The six-week time frame between completion of the course and collection of data also limits the chances for exposure to these events as indicated by responses to the question related to opportunities to practise skills learnt during the course.

Most studies investigating knowledge and skill retention find variable levels of decline over different time frames, which is often explained by the inability to control relevant variables that could impact on the longer term results, such as levels of prior knowledge, proficiency of precourse skills, clinical experience and encountering relevant situations in the workplace. ${ }^{25-27}$ Again, it is crucial to reinforce the benefits of short courses through continuing clinical experience ${ }^{28}$ as repetition promotes skill retention, ${ }^{29}$ and where opportunities to manage rare clinical situations are limited, access to in-house training should be mandatory to maintain skills.

By measuring confidence and perceived knowledge just six weeks after training, we have been able to show that for some participants, even after this short period of time, there is loss of confidence and perceived knowledge. The corollary of this relatively short retention in certain areas appears to support the old adage 'use it or lose it'. Nonetheless, despite this decline, when compared to precourse levels, participants still retained a significantly increased amount of confidence and perceived knowledge as a result of completing the Australian ALSO course, thereby providing evidence that the course exerted a positive effect on confidence and theoretical knowledge to manage obstetric emergencies in the short term. However, as assessment of actual knowledge retention, or its clinical impact, was a limitation of this study, whether participants' enhanced confidence and knowledge translates to the workplace resulting in improved clinical outcomes for mothers and babies is unknown.

Ideally, a course evaluation would measure outcomes in practice. $^{30}$ Although ALSO outcomes have successfully been measured in a hospital in Tanzania, ${ }^{16}$ the geographical diversity of participants' workplaces in Australia and the differences in opportunities for participants to use skills learned during a course (entirely dependent on the type of institution where they practise and the level of maternity care it provides) make a more objective evaluation of learning outcomes from the Australian ALSO course complicated. Whilst recognising the difficulty of this endeavour, nonetheless it should be considered as an important direction for establishing the substantive efficacy of the course.

These research findings contribute valuable information to the merits and usefulness of the ALSO course both nationally and internationally and will hopefully encourage further research in measuring outcomes related to both knowledge and competence following participation in obstetric emergency courses, along with strategies to improve retention of knowledge and skills. 


\section{Acknowledgements}

We are grateful to the Australian ALSO Executive Board for their support of the study, and special thanks go to the participants and the ALSO administrators and Advisory Faculty at targeted courses for their invaluable assistance with participant recruitment and data collection.

\section{Conflict of interest}

Laura Walker is an instructor and Advisory Faculty member for the Australian ALSO course. Although she was Advisory Faculty on the pilot course of this study, she did not teach at the course and was not in attendance at any of the courses during the main study.

\section{References}

1 Sullivan E, Hall B, King J. Maternal Deaths in Australia 2003-2005. Canberra: Australian Institute of Health and Welfare, 2008.

2 Catling-Paull C, McDonnell N, Moores A, Homer CSE. Maternal mortality in Australia: learning from maternal cardiac arrest. Nurs Health Sci 2011; 13: 10-15.

3 Kildea S, Pollock WE, Barclay L. Making pregnancy safer in Australia: the importance of maternal death review. Aust $N Z$ F Obstet Gynaecol 2008; 48: 130-136.

4 Upadhyay K, Scholefield H. Risk management and medicolegal issues related to postpartum haemorrhage. Best Pract Res Clin Obstet Gynaecol 2008; 22: 1149-1169.

5 Centre for Maternal and Child Enquiries (CMACE). The eighth report of the confidential enquiries into maternal deaths in the United Kingdom. Br $\mathcal{F}$ Obstet Gynaecol 2011; 118: $1-203$.

6 Johanson R, Cox C, O’Donnell E et al. Managing obstetric emergencies and trauma (MOET). TOG 1999; 1: 46-52.

7 Cooke H, Foureur M, Kinnear A et al. The development and initiation of the NSW Department of Health interprofessional Fetal welfare Obstetric emergency Neonatal resuscitation Training project (FONT). Aust N Z F Obstet Gynaecol 2010; 50: 334-339.

8 Maouris $\mathrm{P}$, Jennings $\mathrm{B}$, Ford J et al. Outreach obstetrics training in Western Australia improves neonatal outcome and decreases caesarean sections. F Obstet Gynaecol 2010; 30: 6-9.

9 Black RS, Brocklehurst P. A systematic review of training in acute obstetric emergencies. Br F Obstet Gynaecol 2003; 110: 837-841.

10 Nielsen PE, Goldman MB, Mann S et al. Effects of teamwork training on adverse outcomes and process of care in labor and delivery: a randomized controlled trial. Obstet Gynecol 2007; 109: 48-55.

11 Siasssakos D, Crofts JF, Winter C et al. The active components of effective training in obstetric emergencies. Br F Obstet Gynaecol 2009; 116: 1028-1032.

12 Beasley JW, Damos JR, Roberts RG, Nesbitt TS. The advanced life support in obstetrics course: a national program to enhance obstetric emergency skills and to support maternity care practice. Arch Fam Med 1994; 3: 1037-1041.
13 Bower DJ, Wolkomir MS, Schubot DB. The effects of the ALSO course as an educational intervention for residents. Fam Med 1997; 29: 187-193.

14 Taylor HA, Kiser WR. Reported comfort with obstetrical emergencies before and after participation in the Advance Life Support in Obstetrics course. Fam Med 1998; 30: 103-107.

15 Dauphin-McKenzie N, Celestin MJ, Brown D, GonzálezQuintero VH. The advanced life support in obstetrics course as an orientation tool for obstetrics and gynaecology residents. Am $\mathcal{F}$ Obstet Gynecol 2007; 196: 27-28.

16 Sorensen BL, Rasch V, Massawe S et al. Advanced life support in obstetrics (ALSO) and post-partum hemorrhage: a prospective intervention study in Tanzania. Acta Obstet Gynecol Scand 2011; 90: 609-614.

17 Clark-Carter D. Quantitative Psychological Research: The Complete Student's Companion, 3rd edn. New York: Psychology Press, 2009.

18 Cohen J. Statistical Power Analysis for the Behavioural Sciences, 2nd edn. Hillsdale, NJ: Erlbaum, 1988.

19 Bartlett JE, Kotrlik JW, Higgins C. Organizational research: determining appropriate sample size in survey research. ITLPF 2001; 19: 43-50.

20 Sullivan EA, Moran K, Chapman M. Term breech singletons and caesarean section: a population study, Australia 19912005. Aust N Z F Obstet Gynaecol 2009; 49: 456-460.

21 Australian Resuscitation Council. Guideline 13.1: Introduction to Resuscitation of the Newborn Infant. ????:Australian Resuscitation Council, 2010.

22 Sørensen JL, Løkkegaard E, Johansen $M$ et al. The implementation and evaluation of a mandatory multiprofessional obstetric skills training program. Acta Obstet Gynecol 2009; 88: 1107-1117.

23 Shapiro AM. How including prior knowledge as a subject variable may change outcomes of learning research. Am Educ Res f 2004; 41: 159-189.

24 Kroushev A, Beaves M, Jenkins V, Wallace EM. Participant evaluation of the RANZCOG fetal surveillance education program. Aust N Z F Obstet Gynaecol 2009; 49: 268-273.

25 Gass DA, Curry L. Physicians' and nurses' retention of knowledge and skill in cardiopulmonary resuscitation. Can Med Assoc F 1983; 128: 550-551.

26 Crofts JF, Ellis D, Draycott TJ et al. Change in knowledge of midwives and obstetricians following obstetric emergency training: a randomised controlled trial of local hospital, simulation centre and teamwork training. Br F Obstet Gynaecol 2007; 114: 1534-1541.

27 Govender K, Rangiah C, Ross A, Campbell L. Retention of knowledge of and skills in cardiopulmonary resuscitation among healthcare providers after training. S Afr Fam Pract 2010; 52: 459-462.

28 Patel M, Oosthuizen G, Child S, Windsor JA. Training effect of skills courses on confidence of junior doctors performing clinical procedures. N Z Med F 2008; 121: 1275.

29 Riegel B, Birnbaum A, Aufderheide TP et al. Predictors of cardiopulmonary resuscitation and automated external defibrillator skill retention. Am Heart f 2005; 150: 927-932.

30 Kirkpatrick D. Great ideas revisited: techniques for evaluating training programs: revisiting Kirkpatrick's four-level model. Training Dev 1996; ????: ????-????. 